\title{
Bronchiectasis: how to be an orphan with many parents?
}

\author{
Pieter C. Goeminne ${ }^{1}$ and Anthony De Soyza ${ }^{2}$
}

Affiliations: ${ }^{1}$ Dept of Respiratory Medicine, AZ Nikolaas, Sint-Niklaas, Belgium. ${ }^{2}$ Respiratory Dept, Institute of Cellular Medicine, Newcastle University and Freeman Hospital, Sir William Leech Research Centre, Newcastle upon Tyne, UK.

Correspondence: Anthony De Soyza, Respiratory Dept, Institute of Cellular Medicine, 3.131 Leech Building, Newcastle University and Freeman Hospital, Sir William Leech Research Centre, Newcastle upon Tyne, UK.

E-mail: anthony.de-soyzaßncl.ac.uk

-

@ERSpublications

Bronchiectasis, an orphan disease in the spotlight: more common than previously thought yet lots still to discover http://ow.ly/Ut1eT

When René Laennec first described bronchiectatic lesions, he wrote: "Je me contenterai donc de donner deux exemples propres à faire connaître plus amplement l'altération organique assez rare dont il s'agit” [1]. Loosely translated, it shows us that during his discovery he had the conviction that bronchiectatic lesions were a rather rare phenomenon. However, at that time, Laennec was the first and only person to characterise these lesions, suggesting that his contemporaries had completely overlooked their existence. What is unsought will go undetected.

More than a decade later, Laennec updated his works for the English publication of his manuscript. He now stated that: "The dilatation of the bronchi without being a very common affection, is, however, much less rare than I long conceived it to be" [2]. Perhaps one of Laennec's few failings was to develop a consensus that this was more commonly encountered than felt. Hence despite Laennec's experience that bronchiectasis was more common once it was specifically sought, authors at the end of the 20th and the beginning of the 21st century still followed the initial dogma that bronchiectasis was a rare or orphan disease $[3,4]$. What is unsought will go undetected, but look and you will find.

However, in the past decade, we have finally learned from Laennec's later observations. Compelling data show that the prevalence of bronchiectasis surpasses the threshold of five per 10000 population for the definition of an orphan disease, as defined by the European Union [5]. A recent population-based estimation of bronchiectasis prevalence in Germany calculated an overall prevalence rate of 67 per 100000 in 2013, with an even higher prevalence of 228 per 100000 in men aged 75-84 years [6]. These European observations concur with prior data from the USA that demonstrated bronchiectasis is much more common than widely perceived. These US data suggested an even higher overall annual prevalence of 370 cases per 100000 person-years or 537 cases per 100000 person-years in women aged 80-84 years [7]. These data are from Medicare datasets and may not reflect the whole of the US population, nevertheless they confirm that this condition is both an international issue and more frequent than perceived. Respiratory physicians frequently encounter bronchiectasis, with one estimate suggesting that $2.6 \%$ of all respiratory problems in a hospitalised population are linked with bronchiectasis [8].

In this issue of the European Respiratory Journal, the data from Quint et al. [9] are even more compelling, clearly showing that both prevalence and incidence of bronchiectasis are quickly rising in the UK. For incidence, rates increased rapidly between 2004 and 2013 and across almost all ages. For the population

Received: Sept 212015 | Accepted after revision: Oct 082015

Support statement: Support was provided by the Medical Research Council (grant number: MR/L011263/1). Funding information for this article has been deposited with FundRef.

Conflict of interest: Disclosures can be found alongside the online version of this article at erj.ersjournals.com

Copyright OERS 2016 
aged 70-79 years, incidence increased from 69.72 in 2003 to 125.74 per 100000 person-years in 2013. Similar increases were seen for point prevalence. QuinT et al. [9] demonstrate that, in 2013, the overall prevalence per 100000 ranged from 43.4 in the group aged 18-30 years to a staggering 1239.7 in the group aged 70-79 years.

It remains unclear why there is consistent reporting of increased incidence and prevalence of bronchiectasis. One would expect that in the developed world with improved living standards and less severe childhood respiratory infections, post-infectious bronchiectasis would be decreasing. In some parts of the world, poor healthcare access, isolation, poverty, overcrowding and poor living conditions will remain a cause of a high prevalence of bronchiectasis [10]. However, Quint et al. [9] interestingly demonstrate that in the UK bronchiectasis is more common in patients with higher socioeconomic status as measured by the Index of Multiple Deprivation. The explanation for these findings remains to be established. Clearly, other reasons must be sought. One of them is a change in diagnostic testing rates such as the increasing use of computed tomography (CT). IMV, a market research company with interest in imaging, estimate that 81.2 million CT procedures were performed in the USA in 2014 compared with 3 million in 1980 in their CT market outlook report $[11,12]$. These figures may explain the relatively high rates of HIV-associated bronchiectasis as an underlying aetiology reported by QuiNT et al. [9], when compared with prior case series. The HIV population is known to be at risk of opportunistic infections, interstitial lung diseases and malignancy, and may have greater rates of CT testing than other aetiologies of bronchiectasis. Ascertainment bias is a possible limitation of this study, although perhaps the learning point is that CT scans do help delineate pathology in those with recurrent lower respiratory tract infections or symptoms and should be applied more frequently in general respiratory clinics. Hence one reason for diagnosing bronchiectasis more frequently is either the wider use of CT scanning or the broadening of recognised conditions associated with bronchiectasis.

A second possible explanation for the increasing rates of bronchiectasis detection is the increasing awareness that the common lung diseases asthma and chronic obstructive pulmonary disease (COPD) are closely linked with bronchiectasis. In 1990, researchers from Hong Kong reported 27\% of their non-cystic fibrosis bronchiectatic patients had asthma [13]. QuinT et al. [9] ascertained that asthma was present in $42.5 \%$ of the patients. Even with some incorrect diagnoses, this is a large proportion of the patients. Theoretically, asthma can both precede and follow the advent of bronchiectasis. Airway obstruction in asthma with mucus plugging and decreased mucociliary clearance can predispose to persistent infection and permanent airway damage. By contrast, the "ectatic" airways may predispose to bronchial hyperreactivity through either a shared T-helper cell (Th)2 pathophysiology or through retention of fungi or other inhaled antigens through increased epithelial permeability. It is clear that many questions remain unanswered in this interaction between asthma and bronchiectasis. QUINT et al. [9] also reported a diagnosis of bronchiectasis and COPD in $36.1 \%$ of their patients which is an area of increasing interest. Bronchiectasis-COPD overlap syndrome (BCOS) is now considered both a valid and important entity by the BRONCH-UK group [14]. In their recommendations, BRONCH-UK stated that anatomical airway abnormalities of bronchiectasis in patients with primary COPD are best considered a phenotype of the COPD disease spectrum and that further work is needed to define the pathogenesis and clinical consequences of this phenotype, particularly in terms of prognosis and whether the presence of anatomical bronchiectasis should alter the therapeutic approach. This is important given the number of new therapies that may have disease modifying effects in COPD that could be applied to bronchiectasis and the increased mortality reported in BCOS [15-17].

A variety of aetiologies are known to cause bronchiectasis. Understanding why there are such broad ranges in the reported bronchiectasis aetiologies across the available case series will be enormously helpful in understanding not only the disease burden but also in planning healthcare provision (table 1). Tighter definitions to aid better aetiological characterisations are needed to allow clinicians to understand the differences between countries and to truly identify those sub-groups defined by aetiology which are at greatest risk of poor outcomes (figure 1).

With this increasing body of evidence it is clear that the iceberg known as "bronchiectasis" has much remaining to be discovered beneath our current superficial levels of understanding. One can argue that bronchiectasis is therefore common yet rarely studied and this is perhaps why "orphan disease" may still be an appropriate term. The collective prevalence data available and the large number of unknowns in key areas compel us to combine forces to better research bronchiectasis [25]. It was clear to researchers interested in this field that there was a need for databases and biobanked patient cohorts, which will allow us to break new ground in our research endeavours. There are an increasing number of clinicians and researchers working together as evidenced by the developing national collaborations (for examples see: www.bronch.ac.uk; http://lungfoundation.com.au/health-professionals/bronchiectasis-registry/; and www.copdfoundation.org/Research/Bronchiectasis-Research-Registry/Learn-More.aspx). Harmonising such 
TABLE 1 Aetiologies of bronchiectasis across multiple case series

\begin{tabular}{|c|c|c|c|c|c|c|c|c|c|c|c|c|c|}
\hline $\begin{array}{l}\text { First author } \\
\text { [ref.] }\end{array}$ & $\begin{array}{c}\text { Subjects } \\
n\end{array}$ & Country, year & Idiopathic & $\begin{array}{c}\text { Post- } \\
\text { infective }\end{array}$ & $\begin{array}{l}\text { Immuno- } \\
\text { deficiency }\end{array}$ & COPD & CTD & IBD & GORD & Asthma & ABPA & $\begin{array}{c}\text { Genetic/ } \\
\text { congenital }\end{array}$ & Other \\
\hline Quint [9] & 18793 & UK, 2015 & 34 & & 1 & $36^{\#}$ & 11 & 2.8 & & $43^{\#}$ & 1.8 & & $\mathrm{HIV}=7$ \\
\hline$Q_{1}[19]$ & 476 & China, 2015 & 66 & 19 & 4 & & & & & & & & \\
\hline McDonnell [20] & 155 & UK, 2015 & 37 & 21 & 7 & 10 & 6 & 3 & 2 & 7 & 1 & 1 & \\
\hline GoEMINNE [16] & 245 & Belgium, 2014 & 32 & 20 & 7 & 17 & 11 & 2 & & & 6 & 5 & \\
\hline Chalmers [21] & 1310 & $\begin{array}{c}4 \text { EU countries, } \\
2014\end{array}$ & 43 & 20 & & & 7 & 2 & & & 8 & & 6 \\
\hline ANWAR [22] & 189 & UK, 2013 & 43 & 24 & 1 & 12 & 5 & 2 & 1 & 3 & 4 & 3 & \\
\hline Pasteur [23] & 150 & UK, 2000 & 53 & 30 & 8 & & 3 & 1 & 4 & & 7 & 3 & 3 \\
\hline Nicotra [24] & 123 & USA, 1995 & 30 & 42 & & & & & & & & 4 & 1 \\
\hline
\end{tabular}

Aetiologies were extracted from selected case series of bronchiectasis. Data are presented as \%, unless otherwise stated. COPD: chronic obstructive pulmonary disease; CTD: connective tissue disease land/or rheumatoid arthritis); IBD: inflammatory bowel disease; GORD: gastro-oesophageal reflux disease; ABPA: allergic bronchopulmonary asthma; EU: European Union. \#: either comorbidities or aetiologies (see QUINT et al. [9]). Adapted from a slide provided by J. Chalmers (University of Dundee, Dundee, UK).

databases and international collaboration efforts have resulted in the recently launched European Multicentre Bronchiectasis Audit and Research Collaboration (EMBARC; www.bronchiectasis.eu). The aim of this collaborative, pan-European database is to tackle the lack of data regarding epidemiology, comorbidities, pathophysiology, severity and prognosis. Interested clinicians and researchers can participate in this pan-European endeavour, thereby contributing to the significant unmet needs in bronchiectasis knowledge $[25,26]$. Importantly there are aims to use common data platforms for cohorts assembled outside Europe so that truly international comparisons will be possible between patients from multiple continents. Our collective challenge is to utilise this spirit of collaboration and the anticipated large pre-assembled cohort to underpin competitive bids for research funding to tackle our knowledge gaps and move us away from the empirical nature of most treatments currently used in bronchiectasis

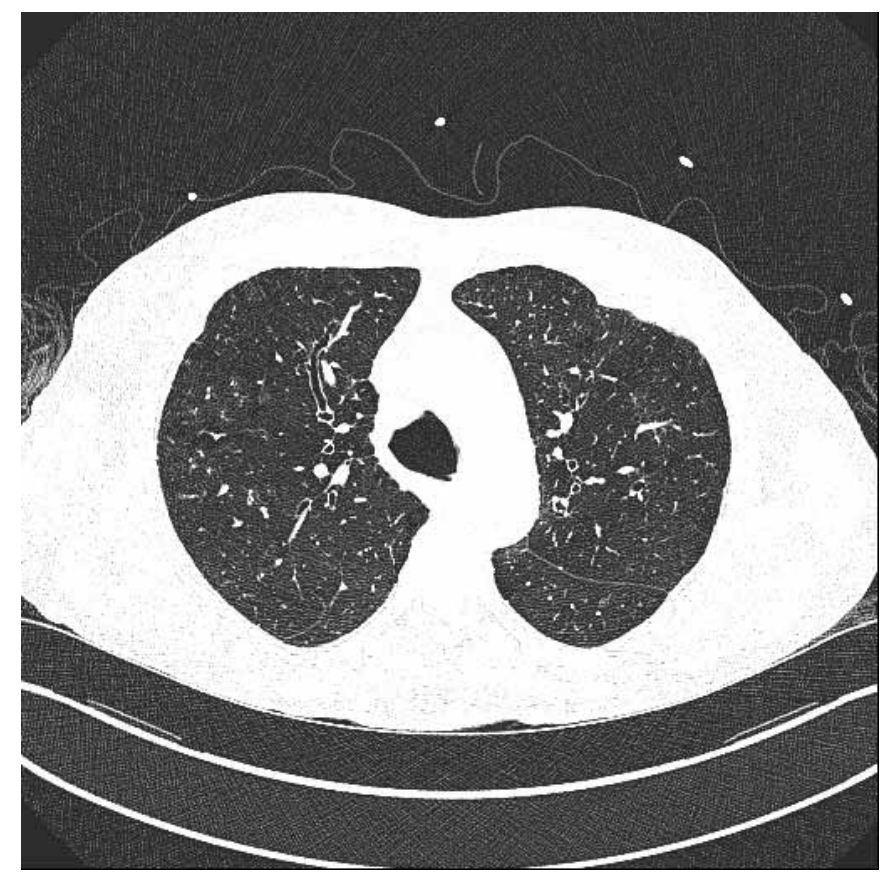

FIGURE 1 Defining bronchiectasis aetiologies: this patient had a diagnosis of chronic obstructive pulmonary disease based on smoking history and airflow limitation. The computed tomography scan indeed shows apical emphysema. However, this scan also shows bronchiectasis and a dilated trachea suggesting Mounier-Kuhn syndrome as an aetiology for the bronchiectasis. Reviewing the history carefully showed recurrent childhood infections further supporting this as an aetiology. As bronchiectasis-COPD overlap syndrome has a poorer outcome, defining the aetiology of bronchiectasis is important. 
[27-29]. At the very least variation in practice between centres and/or countries may allow some evidence synthesis to identify regimens that may be associated with better stability.

Partly thanks to the work of Quint et al. [9] and others, we can now definitely state that bronchiectasis is no longer either an uncommon or unimportant "orphan" disease. We propose that we now have clearer insights into the scale of the problem. Furthermore we propose that bronchiectasis is undergoing a renaissance. Key therapeutic advances and understanding of the natural history will be enhanced through collaborative working and developing prospectively characterised patients who can be entered into observational and interventional studies.

\section{References}

1 Laennec RTH. De l'Auscultation Médiate ou Traité du Diagnostic des Maladies des Poumons et du Coeur. Paris, Brosson \& Chaudé, 1819; pp. 124-138.

2 Laennec RTH, Forbes J. A treatise on the diseases of the chest and on mediate auscultation. New York, Samuel Wood \& Sons, Philadelphia, Desilver, Thomas \& Co, 1835; 2: 100-112.

3 Barker AF. Bronchiectasis. N Engl J Med 2002; 346: 1383-1393.

4 Keistinen $\mathrm{T}$, Säynäjäkangas $\mathrm{O}$, Tuuponen $\mathrm{T}$, et al. Bronchiectasis: an orphan disease with a poorly-understood prognosis. Eur Respir J 1997; 10: 2784-2787.

5 European Commission. Policy: rare diseases - what are they? http://ec.europa.eu/health/rare_diseases/policy/index_en.htm Date last accessed: September 18, 2015.

6 Ringshausen FC, de Roux A, Diel R, et al. Bronchiectasis in Germany: a population-based estimation of disease prevalence. Eur Respir J 2015; 46: 1805-1807.

7 Seitz AE, Olivier KN, Adjemian J, et al. Trends in bronchiectasis among medicare beneficiaries in the United States, 2000 to 2007. Chest 2012; 142: 432-439.

8 Goeminne PC, Scheers H, Decraene A, et al. Risk factors for morbidity and death in non-cystic fibrosis bronchiectasis: a retrospective cross-sectional analysis of CT diagnosed bronchiectatic patients. Respir Res 2012; 13: 21.

9 Quint JK, Millett ERC, Joshi M, et al. Changes in the incidence, prevalence and mortality of bronchiectasis in the UK from 2004 to 2013: a population-based cohort study. Eur Respir J 2016; 47: 186-193.

10 Singleton R, Morris A, Redding G, et al. Bronchiectasis in Alaska Native children: causes and clinical courses. Pediatr Pulmonol 2000; 29: 182-187.

11 Brenner DJ, Hall EJ. Computed tomography - an increasing source of radiation exposure. N Engl J Med 2007; 357: 2277-2284.

12 IMVinfo. 2014 CT Market Summary Report. Des Plains, IMV Medical Information Division, 2014. www.imvinfo. com/index.aspx?sec $=$ ct\&sub $=$ dis\&itemid $=200081$

13 Ip MS, So SY, Lam WK, et al. High prevalence of asthma in patients with bronchiectasis in Hong Kong. Eur Respir J 1992; 5: 418-423.

14 Hurst JR, Elborn JS, De Soyza A, et al. COPD-bronchiectasis overlap syndrome. Eur Respir J 2015; 45: 310-313.

15 De Soyza A, Calverley PM. Large trials, new knowledge: the changing face of COPD management. Eur Respir J 2015; 45: 1692-1703.

16 Goeminne PC, Nawrot TS, Ruttens D, et al. Mortality in non-cystic fibrosis bronchiectasis: a prospective cohort analysis. Respir Med 2014; 108: 287-296.

17 Gatheral T, Kumar N, Sansom B, et al. COPD-related bronchiectasis; independent impact on disease course and outcomes. COPD 2014; 11: 605-614.

18 Guan WJ, Gao YH, Xu G, et al. Aetiology of bronchiectasis in Guangzhou, southern China. Respirology 2015; 20: 739-748.

19 Qi Q, Wang W, Li T, et al. Aetiology and clinical characteristics of patients with bronchiectasis in a Chinese Han population: a prospective study. Respirology 2015; 20: 917-924.

20 McDonnell MJ, Jary HR, Perry A, et al. Non cystic fibrosis bronchiectasis: a longitudinal retrospective observational cohort study of Pseudomonas persistence and resistance. Respir Med 2015; 109: 716-726.

21 Chalmers JD, Goeminne P, Aliberti S, et al. The bronchiectasis severity index. An international derivation and validation study. Am J Respir Crit Care Med 2014; 189: 576-585.

22 Anwar GA, McDonnell MJ, Worthy SA, et al. Phenotyping adults with non-cystic fibrosis bronchiectasis: a prospective observational cohort study. Respir Med 2013; 107: 1001-1007.

23 Pasteur MC, Helliwell SM, Houghton SJ, et al. An investigation into causative factors in patients with bronchiectasis. Am J Respir Crit Care Med 2000; 162: 1277-1284.

24 Nicotra MB, Rivera M, Dale AM, et al. Clinical, pathophysiologic, and microbiologic characterization of bronchiectasis in an aging cohort. Chest 1995; 108: 955-961.

25 De Soyza A, Brown JS, Loebinger MR, et al. Research priorities in bronchiectasis. Thorax 2013; 68: 695-696.

26 EMBARC. The European Bronchiectasis registry. www.bronchiectasis.eu Date last accessed: September 18, 2015.

27 Pasteur MC, Bilton D, Hill AT, et al. British Thoracic Society guideline for non-CF bronchiectasis. Thorax 2010; 65: Suppl., i1-i58.

28 Hill AT, Welham S, Reid K, et al. British Thoracic Society national bronchiectasis audit 2010 and 2011. Thorax 2012; 67: 928-930.

29 Vendrell M, de Gracia J, Olveira C, et al. Diagnostico y tratamiento de las bronquiectasias. SEPAR [Diagnosis and treatment of bronchiectasis. Spanish Society of Pneumology and Thoracic Surgery]. Arch Bronconeumol 2008; 44: $629-640$. 